\title{
Dental Anomalies in Patients with Down Syndrome
}

\author{
Mari Eli Leonelli de MORAES ${ }^{1}$ \\ Luiz Cesar de MORAES ${ }^{1}$ \\ Gustavo Nogara DOTTO ${ }^{2}$ \\ Patrícia Pasquali DOTTO ${ }^{2}$ \\ Luis Roque de Araújo dos SANTOS ${ }^{1}$ \\ ${ }^{1}$ Department of Diagnosis and Surgery, Area of Radiology, School of Dentistry of São José dos Campos,
State University of São Paulo, São José dos Campos, SP, Brazil
${ }^{2}$ Department of Medical Physics, Franciscan University Center, Santa Maria, RS, Brazil
}

The purpose of the present study was to evaluate the incidence of dental anomalies in Brazilian patients with Down syndrome. A sample with 49 panoramic x-rays of syndromic patients aged 3 to 33 years ( 22 male and 27 female) was used. The characteristics of dental anomalies were observed in the panoramic radiographs in both the primary and permanent dentition, according to the ICD (International Classification of Diseases). The corresponding tables and percentile analysis were elaborated. There was a high incidence of syndromic patients with different types of anomalies, such as taurodontism (50\%), proven anodontia (20.2\%), suspected anodontia $(10.7 \%)$, conic teeth $(8.3 \%)$ and impacted teeth (5.9\%). In conclusion, patients with Down syndrome presented a high incidence of dental anomalies and, in most cases, the same individual presented more than one dental anomaly.

Key Words: Down syndrome, trisomy 21, tooth, dental anomalies, radiography, panoramic radiograph.

\section{INTRODUCTION}

Down syndrome, also denominated as trisomy 21 , is a genetic alteration in which the affected individuals carry an extra chromosome $21(1,2)$. The craniofacial and oral features involved in Down syndrome include brachycephaly (condition where the head is disproportionately wide), usually small nose associated with a low nasal bridge, small maxilla, ogival palate and tong with fissures and papillary hypertrophy (2). Children with Down syndrome have a smaller brain volume than other children. Previously unreported reductions in parietal cortex, oft-reported reductions in the temporal lobe and improper neural development might be responsible for the particular features of mental retardation that in some way result from trisomy 21 (3). There is no significant difference in dental arch shape between Down syndrome patients and non-syndromic subjects. High frequency of shelf-like palate is decreasing by age.
Results indicate that palatal vault morphology is subjected to age-related changes (4). These individuals have a more hypoplastic facial middle third with reduced nasal protrusion and a smaller lower facial third (mandible) than non-syndromic subjects. Computerized anthropometry can be used for quantitative examination of the facial characteristics of Down syndrome patients (5).

The teeth of these patients present complete mineralization, but with a great variation in the eruption pattern, although it maintains a certain similarity in the sequence and symmetry. It is common to find cases of periodontal disease, and lower incidence of caries in Down syndrome patients (6). The higher prevalence of periodontal disease is probably related to the impaired host response rather than to specific periodontal pathogens (7). The low caries prevalence seems to be due to immune protection caused by the elevated salivary $S$. mutans specific IgA concentrations (8).

Dental anomalies are very common, both in the

Correspondence: Profa. Dra. Mari Eli Leonelli de Moraes, Radiologia Dental, Faculdade de Odontologia de São José dos Campos, UNESP, Engenheiro Francisco José Longo, 777, Vila Adyana, 12245-000 São José dos Campos, SP, Brasil. Tel: +55-12-3947-9055. Fax: +55-123947-9010. e-mail: eli@fosjc.unesp.br 
primary and permanent teeth, and in the patients with Down syndrome, dental anomalies occur with an incidence five times greater than in the normal population $(9,10)$. In the primary dentition, the most commonly absent teeth are lateral incisors, while in the permanent dentition, third molars, second premolars and lateral incisors, in this sequence, are the most frequently missing teeth (11). Desai (12) described the oral anomalies that may require medical consultation, but also emphasized that these patients are routinely managed in an office setting to treat cases of microdontia, hipoplasia, partial anodontia, taurodontism and others manifestations.

According to Seagriff-Curtin et al. (13), the most common dental associated with Down syndrome are variations in tooth number and morphology. Tooth eruption may be delayed, may occur in an unusual order and can be 2 to 3 years behind a child's normal eruption pattern. Over-retained primary teeth are also common. There is a high incidence of impacted teeth and hypodontia is a frequent finding. Peg laterals, shovel-shaped incisors and taurodontic teeth are often observed.

The purpose of this study was to evaluate the incidence of dental anomalies in Brazilian patients with Down syndrome. The authors understand that this study is of great interest and can contribute to the treatment of these special needs patients.

\section{MATERIAL AND METHODS}

This study used a sample of 49 panoramic x-rays of patients with Down syndrome. The patients were Brazilians subjects aged 3 to 33 years (22 male and 27 female) and were recruited from the Center of Studies and Treatment of Special Needs Patients at the School of Dentistry of São José dos Campos, UNESP, Brazil. The radiographs were taken during dental treatment after parental consent had been granted. The study design was approved by the institutional Ethics in Research Committee (Protocol \#079/2003).

The dental anomalies were evaluated by interpretation of the panoramic radiographs in a lightbox by 2 experienced observers (radiology specialists). The patient was not submitted to clinical examination. The collected data were individually logged verifying the type and incidence of the dental anomalies in each panoramic radiograph, according to the International Classification of Diseases (ICD) (14), tooth eruption and pattern developmental disturbances (K00-0 until K00-9), as follows: 1 - Dental Anomalies of Shape: 1.1 macrodontia, 1.2 microdontia, 1.3 gemination, 1.4 fusion, 1.5 dens in dente (dens invaginatus), 1.6 ectopic enamel, 1.7 amelogenesis imperfecta, 1.8 dentinogenesis imperfecta, 1.9 Hutchinson's teeth, 1.10 dilaceration, 1.11 taurodontism, 1.12 conic teeth; 2 - Dental Anomalies of Number: 2.1 ectodermal dysplasia, 2.2 anodontia, 2.3 supernumerary teeth, 2.4 pre-primary dentition, 2.5 post-permanent dentition, 2.6 accessory roots; $3-$ Tooth Eruption Alterations: 3.1 retention of teeth, 3.2 delayed tooth eruption, 3.3 concrescence, 3.4 overeruption.

The characteristics of the dental anomalies observed in the panoramic radiographs in both primary and permanent teeth were recorded according to this classification. The corresponding tables and percentile analysis were elaborated. Figure 1 is a panoramic radiograph of a 11-year-old girl, who presented both presented two associated anomalies with taurodontism and proven anodontia.

\section{RESULTS}

Data analysis considered the frequency and association of dental anomalies, types and incidence in the studied sample, and their relationship with the number of involved teeth.

Table 1 shows that 2 individuals $(4.08 \%)$ presented no dental anomalies, 20 individuals (40.81\%) presented only one anomaly, 21 individuals (42.85\%) presented two associated anomalies, 4 individuals $(8.16 \%)$ presented three associated anomalies, and only 2 individuals $(4.08 \%)$ presented four associated

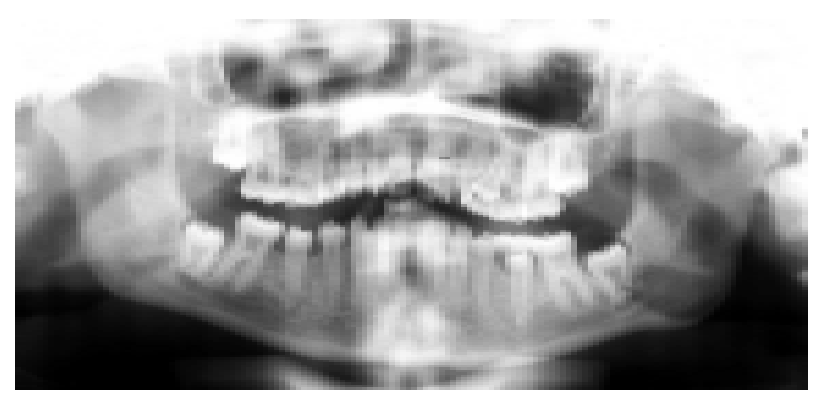

Figure 1. Example of a panoramic radiograph from a 11-year-old girl with Down syndrome, who presented two associated dental anomalies (taurodontism and proven anodontia). 
anomalies. It means that, except for two children aged 3 and 5 years, all studied population presented at least, one type of dental anomaly, which gives a high incidence (95.92\%). These two children had no dental anomalies in the primary teeth and tehir permanent teeth were at the beginning of mineralization stages.

Table 2 shows the types and incidence of dental anomalies found in the studied sample relating the number of affected teeth.

Taurodontism was found in 42 individuals (238 involved teeth), anodontia was present in 17 subjects (44 involved teeth), 9 individuals presented suspected anodontia (19 involved teeth), 7 subjects had conic teeth (11 involved teeth), 5 individuals presented retained teeth (5 involved teeth), and root dilaceration, fusion, microdontia, and delayed tooth formation and eruption were present in 1 patient each, totalizing 8 types of dental anomalies detected 84 times with 329 involved teeth.

The sum of the percentages in Table 2 surpass $100 \%$ because the percentages refer to the incidence of each anomaly in relation to the total sample size and several patients had more than one associated anomaly. This presentation form allows comparing this study to previous works because most studies have analyzed anomalies individually.

\section{DISCUSSION}

Analyzing the anomalies separately, taurodontism was the most common dental anomaly, being identified in $42(85.71 \%)$ out of the 49 examined individuals. It was also noted that taurodontism usually affected several teeth of the same patient and occurred in the same tooth group in most cases.

Table 1. Incidence of the associated anomalies distributed for the 49 patients.

\begin{tabular}{lcc}
\hline Incidence & Number of Patients & Percentages \\
\hline One anomaly & 20 & $40.81 \%$ \\
Two associated anomalies & 21 & $42.85 \%$ \\
Three associated anomalies & 4 & $8.16 \%$ \\
Four associated anomalies & 2 & $4.08 \%$ \\
Subtotal & 47 & $9.92 \%$ \\
Absence of anomalies & 2 & $4.08 \%$ \\
Total & 49 & $100 \%$ \\
\hline
\end{tabular}

Comparing the present results to those of other authors, Alpoz and Eronat (15) investigated the incidence of taurodontism in mandibular molars of 22 Turkish children with Down syndrome aged 6 to 14 years and found that it was present in $66 \%$ of the subjects. The incidence of taurodontism was bilateral in 11 cases and unilateral in only 1 case.

Taurodontism is classified in three categories: hypotaurodont (mild), mesotaurodont (moderate), and hypertaurodont (severe) (16). In the present study, only the presence or absence of taurodontism was considered, leaving the analysis of its severity for future investigations.

The cases of anodontia were divided in two types: proven anodontia and suspected anodontia. Proven anodontia was considered when there was radiographic confirmation of the presence of a primary tooth and absence of its permanent successor tooth germ. Absence of a tooth without the presence of its primary predecessor tooth was considered as suspected anodontia. In the cases were a tooth was missing, but its permanent successor was in formation or if there was a missing tooth and several cases of proven anodontia in the same patient, the hypothesis of anodontia was raised because everything indicated that those teeth had not been formed. As the primary tooth was not present, however, the authors limited to classificate the anomaly as suspected rather than proven anodontia. Most cases of

Table 2. Types, amount and percentages for the anomalies in relation to its incidence for the 49 patients and amount of affected teeth.

\begin{tabular}{lccc}
\hline Anomaly & $\begin{array}{c}\text { Patients } \\
\text { affected } \\
\text { by each } \\
\text { anomaly }\end{array}$ & $\begin{array}{c}\text { Incidence } \\
\text { of each } \\
\text { anomaly }\end{array}$ & $\begin{array}{c}\text { Number } \\
\text { of teeth } \\
\text { per } \\
\text { anomal }\end{array}$ \\
\hline Taurodontism & 42 & $85.71 \%$ & 238 \\
Proven anodontia & 17 & $34.69 \%$ & 44 \\
Suspected anodontia & 09 & $18.36 \%$ & 19 \\
Conic teeth & 07 & $14.28 \%$ & 11 \\
Retained teeth & 05 & $10.20 \%$ & 08 \\
Root dilaceration & 01 & $2.04 \%$ & 05 \\
Fusion & 01 & $2.04 \%$ & 02 \\
Microdontia & 01 & $2.04 \%$ & 01 \\
Tooth formation and & 01 & $2.04 \%$ & 01 \\
delayed eruption & & & \\
\hline
\end{tabular}


suspected anodontia occurred with maxillary lateral incisors. The interpretation approach adopted in the present study was due to the fact that the authors did not have access to the complete patient's records containing their dental history.

Proven anodontia was found in 17 individuals with 44 involved teeth, representing $34.69 \%$ of the sample. The cases with suspected anodontia occurred in 9 subjects with 19 involved teeth, representing $18.36 \%$ of the sample.

A previous study (17) stated that anodontia can occur both in the primary and permanent dentitions. The percentages of affected permanent teeth were: mandibular central incisor: $11 \%$; mandibular lateral incisor: $8 \%$; mandibular premolars: $8 \%$ maxillary lateral incisor: $31 \%$; maxillary canine: $15 \%$ and maxillary premolars: $13 \%$.

Ingalls and Butler (9) reported that the maxillary lateral incisor was congenitally absent in $25 \%$ of the children with Down syndrome. Cohen et al. (18) reported that anodontia occurred in $30 \%$ of the patients, as observed in the present study. Kumasaka et al. (10) analyzing 98 panoramic radiographs of patients with Down syndrome aged 5 to 28 years, verified that $63 \%$ of them presented oligodontia and the most frequently absent tooth was the mandibular lateral incisor (23.3\%). Maxillary second premolars presented an incidence of anodontia of $18.2 \%$, maxillary lateral incisors of $16.5 \%$ and the mandibular second premolars around $15.3 \%$. These authors affirmed that the distribution of anodontia was generally similar for teeth with corresponding positions in both maxillary and mandibular dental arches. Larmour et al. (19), in a retrospective literature review, determined that the prevalence of hypodontia ranged from $2.6 \%$ to $11.3 \%$.

The outcomes of the present study differ from those of the reviewed literature with respect to the most common type of dental anomaly identified in Down syndrome barriers. While the aforementioned authors found anodontia as the most frequent anomaly, our findings point to taurodontism as the most prevalent.

Table 2 shows that, except for taurodontism and anodontia, the other anomalies showed a low incidence. Conic teeth were found in 7 individuals, representing $14.28 \%$ of the 49 examined patients. Retained teeth were observed in 5 individuals, corresponding to $10.20 \%$ of the sample. The other dental anomalies were: 1 case of root dilaceration involving 5 teeth in a same patient; 1 case of fusion involving 2 teeth; 1 case of microdontia; and 1 case of delayed tooth formation and eruption, each one of them representing $2.04 \%$ of the sample.

Scully (20) stated that the eruption of primary and permanent teeth was delayed in individuals with Down syndrome and that the primary teeth not always had their formation completed before the age of 5 , and that alterations in the eruption sequence might occur. Likewise, Coelho and Loevy (17) reported delayed tooth formation and eruption, alteration in the eruption sequence as well as microdontia and dental anomalies of shape. These authors found that $80 \%$ of Down syndrome patients presented alterations in the dental structures.

In this work, delayed tooth formation and eruption were not analyzed in relation to age, but rather in relation to the other present teeth, and hence comparisons are not reliable. A single case of delayed tooth formation and eruption occurred in a 15 -year-old female, in whom all teeth were formed, except for the maxillary second premolar, which was in the beginning of root formation (probably with anodontia of the four third molars).

In conclusion, the presence of the dental anomalies in patients with Down syndrome is quite pronounced, with an incidence of $95.92 \%$. Along their growth and development, these patients present at least 1 type of dental anomaly. These outcomes reinforce that dental care should be directed to prevent and/or control problems that unfortunately reach these special needs patients.

\section{RESUMO}

O objetivo do presente estudo foi avaliar a incidência de anomalias dentárias em indivíduos brasileiros portadores de síndrome de Down. A amostra constou de 49 radiografias panorâmicas de indivíduos portadores com idade entre 3 e 33 anos, 22 do sexo masculino e 27 do sexo feminino. As características radiográficas das radiografias panorâmicas das anomalias dentárias foram observadas tanto nos dentes decíduos quanto permanentes de acordo com CID (Classificação Internacional de Doenças). Foi encontrada uma alta incidência dos mais variados tipos de anomalias, tais como taurodontismo (50\%), anodontia comprovada $(20,2 \%)$, suspeita de anodontia (10,7\%), dentes cônicos $(8,3 \%)$, dentes retidos $(5,9 \%)$ e outras. Pela análise dos resultados podese observar que os indivíduos portadores de síndrome de Down apresentaram uma alta incidência de anomalias dentárias e, na maioria dos casos, um mesmo indivíduo apresentou mais de uma anomalia associada.

\section{REFERENCES}

1. Down JL. Observations on ethnic classification of idiots. Clin 
Lect Rep Lond Hosp 1866;3:259-262.

2. Fischer-Brandies H, Schmid RG, Fischer-Brandies E. Craniofacial development in patients with Down's syndrome from birth to 14 years of age. European J Orthod 1986;8:35-42.

3. Nadel L. Down's syndrome: a genetic disorder in biobehavioral perspective. Genes Brain Behav 2003;2:156-166.

4. Skrinjaric T, Glavina D, Jukic J. Palatal and dental arch morphology in Down syndrome. Coll Antropol 2004;28:841847.

5. Ferrario VF, Dellavia C, Serrao G, Sforza C. Soft tissue facial angles in Down's syndrome subjects: a three-dimensional non-invasive study. Europ J Orthod 2005;27:355-362.

6. Pilcher ES. Dental care for the patient with Down syndrome. J Down Syndr Res Pract 1998;5:111-116.

7. Reuland-Bosma W, Reijden WA, Winkelhoff AJ. Absence of a specific subgingival microflora in adults with Down's syndrome. J Clin Periondontol 2001;28:1004-1119.

8. Lee SR, Kwon HK, Song KB, Choi YH. Dental caries and salivary immunoglobulin a in Down syndrome children. J Paediatr Child Health 2004;40:530-533.

9. Ingalls TH, Butler RL. Mongolism, Implications of dental anomalies. N Engl J Med 1953;19:511-512.

10. Kumasawa S, Miyagi A, Nobuaki, S, Shindo J, Kashima I. Oligodontia: a radiographic comparison of subjects with Down syndrome and normal subjects. SCD Special Care in Dentistry 1997; 17:137-141.

11. Thompson C. The palate in Down's syndrome. Dent Assit 1976;45:16-20.
12. Desai SS. Down syndrome: a review of the literature. Oral Surg Oral Med Oral Pathol Oral Radiol Endod 1997;84:279-285.

13. Seagriff-Curtin P, Pugliese S, Romer M. Dental considerations for individuals with Down syndrome. NY State Dent J 2006; $72: 33-35$

14. World Health Organization - WHO. International Statistical Classification of Diseases and Related Health Problems, 10th Revision. Version for 2007. Available from http:// www.who.int/classifications/apps/icd/icd10online/. Latest access: March 15th, 2007.

15. Alpoz AR, Eronat C. Taurodontism in children associated with trisomy 21 syndrome. J Clin Pediatr Dent 1997;22:3739 .

16. Shaw JC. Taurodont teeth em South African races. Journal of Anatomy 1928;62:476.

17. Coelho CRZ, Loevy HT. Dental aspects of Down syndrome (Original article in Portuguese). Ars Curandi Odontol 1982;8:9-16.

18. Cohen MM, Arvystas MG, Baum BJ. Occlusal disharmonies in trisomy G (Down's syndrome, Mongolism). Am J Orthod 1970;58:367-372.

19. Larmour CJ, Mossey PA, Thind BS, Forgie AH, Stirrups DR. Hypodontia - a retrospective review of prevalence and etiology. Part I. Quintessence Int 2005;36:263-270.

20. Scully C. Down's syndrome: aspects of dental care. J Dent 1975;4:167-174.

Accepted May 15, 2007 